\title{
O CONTROLE PÚBLICO SOB SUSPEITA: UMA REFLEX̃̃O SOBRE A ESTRUTURA DOS TRIBUNAIS DE CONTAS E A EFICIÊNCIA DO CONTROLE EXTERNO SOBRE A PROBIDADE DA ADMINISTRAÇÃO PÚBLICA
}

\author{
Maristella Barros Ferreira de Freitas ${ }^{1}$ \\ Gladstone Avelino Britto ${ }^{2}$
}

\section{RESUMO}

O controle externo, no Brasil, é atribuição constitucional do poder legislativo, com o auxílio dos Tribunais de Contas e tem como finalidade fiscalizar a administração pública quanto à legalidade, impessoalidade, moralidade. Esse tipo de controle pressupõe uma gestão pública, em todos os âmbitos, proba e eficiente, que atenda os anseios da sociedade. As notícias atuais sobre investigação de corrupção na administração pública brasileira indicam que há falhas no controle externo realizado pelos Tribunais de Contas. Este artigo pretende investigar as causas dessa ineficiência e as alternativas que se apresentam para corrigi-la.

Palavras-chave: Tribunal de Contas; controle externo; instituições; improbidade administrativa; fiscalização; administração pública

\section{PUBLIC CONTROL UNDER SUSPECT: A REFLECTION ON THE STRUCTURE OF COURTS OF AUDIT AND THE EFFICIENCY OF EXTERNAL CONTROL ON THE PROBITY OF PUBLIC ADMINISTRATION}

\begin{abstract}
:
The external control in Brazil is constitutional attribution of the legislative power, with the assistance of the Courts of Accounts and aims to oversee the public administration regarding legality, impersonality, morality. This type of control presupposes a public management, in all areas, proba and efficient, that attends to the yearnings of the society. The current news about corruption investigations in the Brazilian public administration indicates that there are flaws in the external control carried out by the Audit Courts. This article intends to investigate the causes of this inefficiency and the alternatives that present to correct it.
\end{abstract}

Keywords: Courts of Audit; External control; institutions; administrative improbity; supervision; public administration

\section{Introdução}

A dificuldade secular dos administradores em separar o espaço publico do privado e de entender que o Estado não é uma ampliação do círculo familiar é atribuída por alguns a um fenômeno cultural. Para Holanda (1995), essa indistinção fundamental entre as duas formas (Estado e família) é prejuízo romântico que teve os seus adeptos mais entusiastas durante o

\footnotetext{
${ }^{1}$ Graduada em Biologia pela UFMT. Graduado em Economia, pela UFMT. Mestre em Política Científica e Tecnológica, pela UNICAMP. Doutora em Política Científica e Tecnológica, pela UNICAMP

${ }^{2}$ Graduado em Economia , pela UFMG. Graduado em Direito, pela UFMT. Mestre em Direito, pela UFMT
} 
século XIX.

Quando o poder público e privado se confundem, cabem às instituições impor os limites dessas duas áreas, de maneira que o patriarcalismo ceda o lugar à burocracia que, na concepção dada por Weber (1999), é uma forma de dominação ordenada mediante regras (leis ou regulamentos administrativos).

Daí a importância de marcos regulatórios eficientes delimitando inequivocadamente tais espaços. Como nas regras de um jogo, as instituições, sejam elas informais ou formais (constituições, leis e direitos de propriedade) contornam os comportamentos humanos e equilibram as satisfações das necessidades individuais e as coletivas.

No Brasil, o marco regulatório para estabelecer a distinção fundamental entre os domínios do privado e do público tem como ponto de partida o artigo 37 da Constituição da República Federativa do Brasil - CRFB (BRASIL, 1988), quando determina a obediência aos princípios de legalidade, impessoalidade, moralidade e outros.

Contudo, impor limites não é suficiente; faz-se necessário certificar se tais limites estão sendo respeitados. Weber (1999) lembra que os dirigentes da administração tem que resolver continuamente problemas políticos e, por isso, controla-los nessa área é a primeira tarefa fundamental do Parlamento.

Nesse contexto, a CRFB estabeleceu em seus artigos 70, 71 e incisos, que o controle sobre da administração pública relativo à verificação do cumprimento dos princípios constitucionais é competencia do Poder Legislativo de cada esfera, com o auxílio dos Tribunais de Contas respectivos, a quem cabe fiscalizar, julgar, sustar ato impugnado e editais licitatórios, aplicar sanções e imputar débito aos responsáveis pelas unidades sob a sua jurisdição, tendo as suas decisões nesse sentido, a eficácia de título executivo.

Dessa forma, os Tribunais de Contas de todas as esferas são legitimados pela Constitiução Federal para serem poderosos guardiões do erário e atuarem ostensivamente no controle externo da legalidade, moralidade, impessoalidade, publicidade e eficiência de toda a administração pública de maneira a coibir a prática de improbidade administrativa.

Por outro lado, as noticias amplamente divulgadas na mídia, indicam que há uma corrupção sistêmica de longa data na administração pública do país, que vem motivando inúmeras operações investigatórias com desdobramentos na esfera judicial federal e estadual.

Paradoxalmente, observa-se que os investigados nessas operações são gestores que 


\section{O controle público sob suspeita: uma reflexão sobre a estrutura dos tribunais de contas e a eficiência do controle externo sobre a probidade da administração pública}

tiveram as contas relativas aos mesmos períodos dos fatos denunciados, aprovadas pelos respectivos Tribunais de Contas, levando à conclusão de que, inegavelmente, o controle externo sobre a administração pública estabelecido na Constituição Federal, não está funcionando como pretendido. A dimensão da ineficiência dos Tribunais de Contas e as causas que contribuem para isso, constituem o problema a ser investigado neste trabalho.

Um sistema de controle externo pautado em instituições fortes e em capacidade técnica elevada de seus integrantes deveria garantir que recursos públicos fossem corretamente aplicados, o que seguramente não é o que vem ocorrendo em nosso país. Por isso, a hipótese a ser investigada é de que a organização atual dos Tribunais de Contas estruturada nas instituições vigentes, prejudica a sua função tutelar do erário.

Diversos aspectos das normas atuais indicam imperfeições que podem afetar o desempenho daquelas entidades fiscalizadoras na sua missão constitucional, fazendo com que o elevado valor alocado no orçamento público anual destinado ao funcionamento dos Tribunais de Contas, não tenha contrapartida equivalente dos serviços por eles prestados, ou seja, a relação custo-benefício resulta desfavoravelmente à sociedade.

Esse panorama indica que é preciso rever o marco regulatório que trata do controle externo na administração pública, no sentido de torná-lo mais efetivo e menos oneroso pois, conforme defendido por North (1990), instituições eficientes e organizações desenvolvidas a partir dessas instituições, reduzem os custos de transação.

Para investigar a problemática aqui delineada, este trabalho tem como objetivo examinar o grau de eficiência do atual modelo Tribunal de Contas, identificar os principais pontos críticos do marco regulatório atual daquelas entidades, avaliar as consequências dessas ineficiências institucionais para o desenvolvimento do País e delinear as alternativas para restabelecimento daquele controle.

A questão tratada neste trabalho representa tema de suma relevância, tanto pelo caráter atual, como também porque o desenvolvimento do nosso País depende de um controle eficiente que saiba traçar com segurança uma verdadeira "linha vermelha" delimitando o espaço publico, do privado.

Analisar as melhores alternativas para corrigir as falhas no controle externo aqui demonstradas, é uma medida urgente, não só pelas ocorrências aqui sintetizadas, como 
também pelo fato de que tramita nas Casas do Congresso Nacional duas PEC's que tratam de alterações estruturais Tribunais de Contas.

Para tanto, a metodologia utilizada inicialmente foi um exame na bibliografia que trata sobre a análise das relações existentes entre instituições jurídicas e a formulação de políticas públicas e, ainda, no marco regulatório brasileiro sobre o assunto.Também foi utilizada como ferramenta metodológica a análise de notícias de corrupção na administração pública veiculadas na mídia, as pesquisas realizadas por entidades ligadas ao tema e levantamento de dados nas páginas da internet dos Tribunais de Contas do Estado do Mato Grosso e do Rio de Janeiro, selecionados na amostra.

\section{Breve Revisão de Literatura}

A análise do grau de eficiência do marco regulatório que trata sobre os Tribunais de Contas requer, preliminarmente, um exame na literatura a respeito das instituições, que possibilite ume reflexão da sua importância para o desenvolvimento econômico de um País.

North (1990), um dos fundadores do programa de pesquisa da Nova Economia Institucional - NEI, introduz um novo componente no desenvolvimento de um país quando afirma que as Instituições afetam o desempenho da economia pelo efeito que tem sobre os custos de mudança e de produção.

Por isso, uma evolução institucional pode ser mais importante para o desenvolvimento econômico, do que avanços tecnológicos (NORTH; DAVIS, 1971).

A ascenção do mundo ocidental, especialmente a Europa Ocidental e Estados Unidos, pode ser explicada, em grande parte, na evolução das instituições durante a transição do feudalismo para o capitalismo no fim da Idade Média, capazes de levar esses países a um crescimento econômico sem precedentes (NORTH;THOMAS, 1973).

Países como a Holanda e Inglaterra foram capazes de desenvolver arranjos institucionais para estimular atividades produtivas durante os séculos XVI a XVII, fundamentais para a criação de mercados modernos e eficientes que possibilitaram o crescimento econômico.

Especialmente na Holanda, North (1991) destaca que uma política de imigração aberta atraiu empresários e métodos eficientes de financiamento do comercio desenvolvidos reduziram os custos de subscrição desse mercado. 


\title{
O controle público sob suspeita: uma reflexão sobre a estrutura dos tribunais de contas e a eficiência do controle externo sobre a probidade da administração pública
}

Por outro lado, a Espanha e a França, na mesma época, não alcançaram a mesma escala nas atividades economicamente produtivas, porque as leis e as organizações criadas naqueles países não favoreciam o seu crescimento. Isso explica, na concepção de North, o que ele denomina de "crescimento errático" na América latina:

\begin{abstract}
Os caminhos divergentes estabelecidos pela Inglaterra e Espanha no Novo Mundo não convergiram apesar dos fatores mediadores de influências comuns ideológicas. No primeiro, desenvolveu-se um quadro institucional que permite uma troca impessoal complexa, necessária à estabilidade política, bem como para capturar os potenciais benefícios econômicos da tecnologia moderna. No ultimo, relações personalistas continuam a ser a chave para muitas das mudanças econômicas e políticas. Elas são a conseqüência de uma estrutura de envolvimento institucional que tem produzido um crescimento econômico errático na América Latina, mas nem estabilidade política, nem econômica, nem a realização do potencial de tecnologia moderna. (NORTH, 1991, p.111).
\end{abstract}

O exercício de poder no qual o público e o privado se confundem representa, na visão de Weber (1999), uma dominação tendente ao patrimonialismo, onde o direito dos associados, converte-se em seu direito próprio, apropriado por ele da mesma forma (em princípio) que um objeto possuído de natureza qualquer.

Corroborando essa teoria de relação personalista predominante no quadro institucional na América latina, Holanda (1995) lembra que essa característica representa um traço marcante no Brasil, herdado de seu País colonizador.

Nas palavras do Autor, "justamente a repulsa firme a todas as modalidades de racionalização e, por conseguinte, de despersonalização tem sido, até os nossos dias, um dos traços mais constantes dos povos de estirpe ibérica" (HOLANDA, 1995, p. 133).

Ao interpretar o nosso passado sob a ótica da história social, Holanda destaca o caráter pessoal nas transações feitas por muitos comerciantes de outros países, com portugueses e castelhanos, nas quais os primeiros sempre exaltaram a conveniência de estabelecer com os segundos, vínculos mais imediatos do que as relações formais que constituem norma ordinária nos tratos e contratos:

Não há dúvida que, desse comportamento social, em que o sistema de relações se edifica essencialmente sobre os laços diretos, de pessoa a pessoa, procedam os principais obstáculos que na Espanha, e em todos os países hispânicos - Portugal e Brasil, inclusive -, se erigem contra a rígida aplicação das normas de justiça e de quaisquer prescrições legais. (Ibid., p. 134).

Essa necessidade de conferir uma conotação pessoal em todos os tipos de relações, especialmente no âmbito da administração pública, termina por representar um sistema no qual os dententores das posições públicas tem dificuldade de compreender a distinção fundamental entre os domínios do privado e do público, caracterizando-se o que Weber (1999) define como dominação patrimonial, na qual a gestão pública apresenta-se como 
assunto de seu interesse particular.

Em sentido inverso, uma moderna administração burocrática é definida por aquele Autor como a ação social de uma formação de dominação baseada numa relação associativa racional.

Holanda (1995) enfatiza que, ao longo da história no Brasil, muito excepcionalmente houve um sistema administrativo puramente burocrático, dedicado a interesses objetivos.

Ao contrário, observa aquele Autor que na história política do nosso País sempre prevaleceu um sistema onde há o predomínio constante das vontades de particulares e no qual a escolha dos homens que irão exercer funções públicas faz-se de acordo com a confiança pessoal e muito menos de acordo com a competência.

Trazendo o assunto para um contexto atual, verifica-se que o terreno politico no Brasil não está muito diferente do sistema predominante no passado. Embora oficialmente exista um sistema burocrático baseado numa relação social regido por regras, leis e regulamentos administrativos, os eventos que vem ocorrendo nos últimos tempos, marcados por operações que investigam atos de corrupção praticada no âmbito da administração pública, reforçam a conclusão de que o exercício do poder em diversas esferas do País, não se reveste da impessoalidade necessária.

Necessário lembrar o importante papel desempenhado pelos órgãos criados num quadro institucional forte. North (1990) enfatiza que não são apenas as instituições que afetam os custos de uma economia, mas também as organizações, assim entendidas como os órgãos politicos, econômicos, sociais e educacionais.

Contudo, pouco adiantaria à economia de um País possuir leis e estrutura organizacional eficientes, se não houver um controle sobre o cumprimento dessas leis.

A preocupação em controlar a gestão pública vem de longa data e mais recentemente, a Organização Internacional das Entidades Fiscalizadoras Superiores INTOSAI $^{3}$, ao estabelecer as Normas Internacionais das Entidades Fiscalizadoras Superiores (ISSAI 100) definiu os postulados básicos da fiscalização pública e, dentre eles, a necessidade do gestor prestar contas de forma eficiente.

\footnotetext{
${ }^{3}$ International Organization of Supreme Audit Institutions - INTOSAI. Organização autônoma, criada para fomenter o intercâmbio de ideias e experiências de auditoria governamental entre as Entidades Fiscalizadoras Superiores dos países membros. Tem sua sede em Viena, Áustria e é composta de 190 países membros, dentre os quais, o Brasil, representado pelo Presidente do Tribunal de Contas da União.
} 


\section{O controle público sob suspeita: uma reflexão sobre a estrutura dos tribunais de contas e a eficiência do controle externo sobre a probidade da administração pública}

Prever em lei a obrigação do gestor de prestar contas é um dos mecanismos disponibilizados ao cidadão para ele exercer o controle sobre a administração pública.

O exame dessa questão e a titularidade do controle externo da administração pública, aplicada na esfera brasileira, será objeto da próxima seção.

\section{Restrições institucionais da administração pública brasileira}

Em linhas gerais, os atos do gestor público estão limitados pela obediência os princípios fundamentais exigidos no artigo 37 da CRFB (BRASIL, 1988):

\footnotetext{
Art. 37. A administração pública direta e indireta de qualquer dos Poderes da União, dos Estados, do Distrito Federal e dos Municípios obedecerá aos princípios de legalidade, impessoalidade, moralidade, publicidade e eficiência e, também, ao seguinte:
}

Com sentido amplo e direto, o caput desse dispositivo constitucional nos parece perfeito, pois reúne todos os mandamentos que devem preceder quaisquer atos administrativos, de forma concomitante, isto é, um princípio não elide o outro e todos devem ser observados ao mesmo tempo.

Outras legislações também tratam de delimitar mais especificamente a gestão pública, detalhando procedimentos, caracterizando os diversos tipos de infrações, tipificando os crimes e estabelecendo as penas deles decorrentes.

Além da exigência relativa aos princípios constitucionais acima referidos, uma outra restrição da gestão de recursos públicos estabelecida institucionalmente no Brasil diz respeito à obrigatoriedade de prestação de contas, como consta claramente estabelecida no dispositivo da CRFB (Ibid.), abaixo transcrito:

\section{Art. $70[\ldots]$}

Parágrafo único. Prestará contas qualquer pessoa física ou jurídica, pública ou privada, que utilize, arrecade, guarde, gerencie ou administre dinheiros, bens e valores públicos ou pelos quais a União responda, ou que, em nome desta, assuma obrigações de natureza pecuniária. (Redação dada pela Emenda Constitucional n. 19/1998).

Por sua vez, a competência do controle externo sobre a administração pública, incluindo julgar a prestação de contas, cabe ao Poder Legislativo, com o auxílio dos Tribunais de Contas respectivos, como estabelecido nos dispositivos daquela Lei Maior (Brasil, 1988):

\footnotetext{
Art. 70. A fiscalização contábil, financeira, orçamentária, operacional e patrimonial da União e das entidades da administração direta e indireta, quanto à legalidade, legitimidade, economicidade, aplicação das subvenções e renúncia de receitas, será exercida pelo Congresso Nacional, mediante controle externo, e pelo sistema de controle interno de cada Poder.

Art. 71. O controle externo, a cargo do Congresso Nacional, será exercido com o auxílio do Tribunal de Contas da União, ao qual compete: (destacou-se)
} 
Nesse ponto, surge a primeira imperfeição relativa ao marco legal que dispõe sobre o órgão que auxiliará o Poder Legislativo na fiscalização da administração pública.

Não há, nesse dispositivo e nem nos seguintes, nenhuma referência ao Poder ao qual os Tribunais de Contas se inserem. E essa condição excepcional de sua constituição, pode ser observada desde a sua origem.

No texto da mensagem enviada em 07 de novembro de 1890 pelo então Ministro da Fazenda, Rui Barbosa, ao Marechal Manoel Deodoro da Fonseca, Chefe do Governo Provisório da República dos Estados Unidos do Brasil, percebe-se claramente a intenção de que a entidade de fiscalização autônoma fosse inserida entre os Poderes Executivo e Legislativo, e não em algum deles:

[...] e a medida que vem propor-vos é a criação de um Tribunal de Contas, corpo de
magistratura intermediaria à administração e à legislatura, que, colocado em posição
autônoma, com atribuições de revisão e julgamento, cercado de garantias - contra quaisquer
ameaças, possa exercer as suas funções vitais no organismo constitucional, sem risco de
converter-se em instituição de ornato aparatoso e inútil. (BARBOSA, 1999:254) - Destacado

Hodiernamente, também não há um consenso dentre os doutrinadores no mundo jurídico a respeito do Poder ao qual pertence o Tribunal de Contas.

Em decorrência da sua função de auxiliar o Poder Legislativo no controle externo alguns doutrinadores defendem ser o Tribunal de Contas integrante desse poder.

Discordando desse entendimento, Britto (2005) assim se expressa:

Feita a ressalva, começo por dizer que o Tribunal de Contas da União não é órgão do Congresso Nacional, não é órgão do Poder Legislativo. Quem assim me autoriza a falar é a Constituição Federal, com todas as letras do seu art. 44, litteris: "O Poder Legislativo é exercido pelo Congresso Nacional, que se compõe da Câmara dos Deputados e do Senado Federal" (negrito à parte). [...] O TCU se posta é como órgão da pessoa jurídica da União, diretamente, sem pertencer a nenhum dos três Poderes Federais. (BRITTO, 2005:60-62).

Para o Tribunal de Contas da União (TRIBUNAL DE CONTAS DA UNIÃO, 2013?), o entendimento majoritário é no sentido de ser o Tribunal um órgão de extração constitucional, independente e autônomo, que auxilia o Congresso Nacional no exercício do controle externo.

Em que pese diferentes posições e a omissão da Constituição Federal sobre o assunto, a Carta Magna é muito incisiva quando estabelece a existência de, tão somente, três Poderes na União.

Nesse sentido, não há como considerar excludente de algum desses poderes, nenhuma Entidade do País, nem mesmo o Tribunal de Contas, principalmente quanto à obrigação de respeitar os princípios constitucionais estabelecidos no artigo 37 daquela Lei 


\section{O controle público sob suspeita: uma reflexão sobre a estrutura dos tribunais de contas e a eficiência do controle externo sobre a probidade da administração pública}

Maior, reproduzido anteriormente.

Não entender o Tribunal de Contas, e da mesma forma o Ministério Público, como integrantes de alguns dos Poderes, significa afirmar que essas instituições, igualmente autônomas, não necessitam obedecer os princípios elencados naquele dispositivo constitucional, o que corresponderia a um despropósito.

De toda a forma, a falta de clareza quanto a esse aspecto já demonstra que as imperfeiçoes institucionais relativas aos Tribunais de Contas reportam desde a sua concepção.

Para identificar os demais fatores responsáveis por comprometer a eficiência do controle na administração pública, proposta deste trabalho, deve-se começar conhecendo a estrutura e a composição dos Tribunais de Contas previstas em lei, o que será feito a seguir.

\section{Composição dos Tribunais de Contas $x$ independência e legitimidade da atuação}

Conforme levantamento realizado por Sakai e Paiva (2014), da ONG Transparência Brasil $^{4}$, com dados de maio/2014 atualizados em outubro/2015, estão na ativa 238 integrantes de 34 Tribunais de Contas do pais, sendo: Tribunal de Contas da União - TCU; 26 Tribunais de Contas Estaduais e 01 do Distrito Federal; 04 Tribunais dos municípios, na Bahia, Ceará, Goiás e Pará; 02 Tribunais de capitais estaduais, Rio de Janeiro e São Paulo.

Anualmente são alocados nos orçamentos de cada esfera, recursos destinados aos Tribunais de Contas respectivos e, de acordo com o levantamento já mencionado, o valor em 2015 variou de $0,3 \%$ a $1,9 \%$ do total do orçamento do Estado respectivo, sendo que dois Estados reservaram quase $2 \%$ em seus orçamentos, para os Tribunais: Roraima e Mato Grosso.

Quanto à composição dos Tribunais de Contas, assim estabeleceu a CRFB (BRASIL, 1988):

\footnotetext{
Art. 73. O Tribunal de Contas da União, integrado por nove Ministros, tem sede no Distrito Federal, quadro próprio de pessoal e jurisdição em todo o território nacional, exercendo, no que couber, as atribuições previstas no art. 96.

$\S 1^{\circ}$ Os Ministros do Tribunal de Contas da União serão nomeados dentre brasileiros que satisfaçam os seguintes requisitos:

I - mais de trinta e cinco e menos de sessenta e cinco anos de idade;

II - idoneidade moral e reputação ilibada;

III - notórios conhecimentos jurídicos, contábeis, econômicos e financeiros ou de administração pública;
}

\footnotetext{
${ }^{4}$ Entidade Não Governamental, representante da Sociedade Civil. Disponível em: http://www.transparencia.org.br/downloads/publicacoes/TBrasil\%120-\%20Tribunais\%20de\%20Contas\%202016.pdf. Acesso em: $12 / 4 / 2017$
} 


\begin{abstract}
IV - mais de dez anos de exercício de função ou de efetiva atividade profissional que exija os conhecimentos mencionados no inciso anterior.

$\S 2^{\circ}$ Os Ministros do Tribunal de Contas da União serão escolhidos:

I - um terço pelo Presidente da República, com aprovação do Senado Federal, sendo dois alternadamente dentre auditores e membros do Ministério Público junto ao Tribunal, indicados em lista tríplice pelo Tribunal, segundo os critérios de antigüidade e merecimento;

II - dois terços pelo Congresso Nacional.
\end{abstract}

A autonomia dos Tribunais de Contas está assegurada no caput do artigo $73 \mathrm{c} / \mathrm{c}$ o artigo 96 daquela Lei e abrange executar seus orçamentos, eleger seus órgãos diretivos, elaborar seus regimentos internos, organizar sua estrutura interna, prover o seu quadro próprio de pessoal e propor a criação e extinção dos cargos e a remuneração de seus serviços auxiliares.

Contudo, é justamente na forma de compor o órgão deliberativo dos Tribunais de Contas estabelecida no dispositivo constitucional acima transcrito, que reside a primeira fragilidade do seu funcionamento como se verá, a seguir.

Contraditoriamente ao previsto no inciso II do art. 37, a investidura no cargo publico de ministros e conselheiros do Tribunal de Contas não depende de aprovação prévia em concurso público e sim de livre escolha do Congresso Nacional/Assembleia legislativas estaduais e do chefe do poder executivo de cada esfera, com estabelecido no $\S 2^{\circ}$ do artigo 73 da CRFB, obedecendo os frágeis critérios estabelecidos no $\S 1^{\circ}$ do mesmo dispositivo.

Essa modalidade de investidura confere aos representantes dos Poderes Executivo e Legislativo a liberalidade de decidir, de acordo com os seus interesses pessoais e em detrimento do interesse público, quem vai integrar, em caráter vitalício, o corpo deliberativo dos Tribunais de Contas. E nem mesmo a determinação contida no $\S 2^{\circ}$ do artigo 73 da Constituição Federal, de que um terço da escolha sob a responsabilidade do chefe do poder executivo recaia entre 02 auditores e procuradores de contas, que são investidos naqueles cargos por concurso público, impede a discricionariedade da indicação, pois estar na lista tríplice prevista naquele dispositivo, recai uma vez mais no campo de interesses pessoais.

A prerrogativa de escolha assegurada por aquele dispositivo constitucional, além do caráter personalista, também possibilita negociações corruptas das vagas, como denunciado na Ação Civil Pública proposta pelo Ministério Público do Estado do Mato Grosso - MPEMT, apontando que em 2009 houve um esquema fraudulento na compra, por 12 milhões, de vaga de Conselheiro no TCE-MT indicado pela Assembleia legislativa, envolvendo conselheiros, deputados estaduais, secretários e governadores.

As investigações naquela Ação Civil Pública culminaram no afastamento imediato, 


\section{O controle público sob suspeita: uma reflexão sobre a estrutura dos tribunais de contas e a eficiência do controle externo sobre a probidade da administração pública}

pela Justiça, de Sérgio Ricardo, conselheiro que assumiu a vaga denunciada e, ainda, o bloqueio de bens no valor de $\mathrm{R} \$ 4$ milhões dele e de outros réus, entre eles o Ministro da Agricultura, Pecuária e Abastecimento, Blairo Maggi (SOARES, 2017).

A discricionariedade conferida pela Constituição Federal àqueles Poderes, também coloca em suspeição a independência e isenção dos membros dos Tribunais de Contas, na medida em que eles serão juízes das contas de quem os escolheu e das contas dos inúmeros “apadrinhados" distribuídos em diversos órgãos da administração pública direta e indireta.

Esse grau de dependência fica bastante visível quando se examina as decisões proferidas pelo pleno daquelas entidades fiscalizadoras sobre as contas de governo estaduais que são, em geral, favoráveis à sua aprovação, e que, tradicionalmente, são mantidos pela Assembleia Legislativa respectiva, a quem cabe o julgamento final daquelas contas.

Exemplos bastante ilustrativos da parcialidade daquelas Entidades Fiscalizadoras, nas apreciações das contas do Poder Executivo, podem ser obtidos em levantamento feito na página eletrônica do TCE-MT (TRIBUNAL DE CONTAS DO ESTADO DE MATO GROSSO, 2017a), selecionado na amostra desta pesquisa.

Fazendo um recorte temporal de 2004 a 2015, verifica-se naquele canal que todos os pareceres prévios emitidos pelo pleno daquele Tribunal sobre as contas do Governo do Estado do Mato Grosso daquele período, foram favoráveis às suas aprovações, abrangendo, inclusive, toda a gestão do Governador Silval da Cunha Barbosa - 2010 a 2014, contrariando em alguns deles o parecer do Ministério Público de Contas, como foi o caso da gestão 2014 - Processo n. 8176-0/2014, cujo Conselheiro Relator do processo, Antônio Joaquim, votou pelo parecer favorável à aprovação, sendo acompanhado pelo pleno - Parecer Prévio n. 04/2015.

Paradoxalmente às decisões favoráveis do TCE-MT exaradas naqueles pareceres, o mesmo ex-governador Silval Barbosa, que está preso preventivamente desde setembro de 2015 foi alvo da operação "Sodoma" deflagrada pela Delegacia Especializada em Crimes Fazendários e Contra a Administração - DEFAZ, que investiga, dentre outras, desvio de dinheiro público em fraudes na concessão de benefícios fiscais ocorridas nos anos 2012 e 2013 e ainda, três desapropriações milionárias pagas pelo governo estadual durante o ano de 2014 no valor total de $\mathrm{R} \$ 31.715 .000,00$, nos quais aquele ex-Governador é apontado como chefe dessa organização criminosa (SECRETARIA DE SEGURANÇA PÚBLICA DO ESTADO DE MATO GROSSO, 2016).

Mesmo descompasso pode ser verificado em relação à apreciação, por aquele TCE- 
MT, das gestões 2011 a 2014 da Agência Estadual de Execução dos Projetos da Copa do Mundo do Pantanal - AGECOPA, sucedida em 2012 pela SECOPA.

Como órgão da administração pública estadual responsável pela execução e fiscalização das ações pertinentes à Copa do Mundo 2014 em Cuiabá, uma das cidades escolhidas para sede daquele evento, a AGECOPA/SECOPA teve as suas gestões 2011 a 2013 submetidas à apreciação dos Tribunais de Contas e julgadas regulares com determinações e recomendações; as contas 2014 não foram apreciadas e estão sobrestadas naquela Entidade ${ }^{5}$.

Em contraste àquelas decisões, a Comissão Parlamentar de Inquérito - CPI instaurada em 2015 na Assembleia Legislativa daquele Estado - ALMT apresentou em outubro de 2016 à Mesa Diretora, o relatório das investigações que conclui pelo desvio de R\$ 541 milhões nas obras da Copa 2014, pedindo o indiciamento de 96 agentes públicos, de dirigentes de 16 empresas e sete consórcios, do ex-governador Silval Barbosa, do expresidente da ALMT, José Geraldo Riva e dos ex-secretários da Agecopa/Secopa (CPI, 2016).

Inegável, portanto, as discrepâncias entre aqueles julgamentos da gestão pública estadual realizados pelo TCE-MT e a denúncia de desvios de recursos públicos praticados pelos gestores no âmbito da administração pública do Estado do Mato Grosso, no mesmo período.

$\mathrm{Na}$ União, a tendência na apreciação das contas de governo da Presidência da República segue a mesma tradição. Em consulta a página da internet do Tribunal de Contas da União - $\mathrm{TCU}^{6}$ verifica-se que as contas do Chefe do Poder Executivo daquela esfera de governo, relativas aos exercícios 2004 a 2008, obtiveram o parecer prévio favorável a aprovação.

Apenas as contas do exercícios 2014 - Relator Min. Augusto Nardes e 2015 - Relator Min. José Múcio Monteiro, é que tiveram pareceres prévios aprovados pelo pleno no sentido de que elas não estavam em condições de serem aprovadas pelo Congresso Nacional e

\footnotetext{
5 Gestão 2011 (Acórdão 706/2012 - Proc. 13123-7/2011, Cons. Rel. Antonio Joaquim), gestão 2012 (Acórdão n. 5845/2013 - Proc. n. 127914/2012, Rel. Cons. Ant. Joaquim), gestão 2013 (Acórdão 2815/2014 - Proc. n. 7144-7/2013, Rel. Cons. Substituto João Batista Camargo), gestão 2014 (Proc. n. 2993-0/2014, Relator José Carlos Novelli, sobrestado em 6/11/2015 até o término da da instrução do Relatório de Obras, Processo no 15.677-9/2015 e execução dos termos de ajustamento de gestão - TAG celebrados entre este Tribunal de Contas, a Secretaria de Estado de Cidades, a Controladoria Geral do Estado e respectivas empreiteiras, objetivando a conclusão de obras vinculados ao evento Copa do Mundo FIFA 2014).

${ }^{6}$ Não foi possível obter informações dos Pareceres Prévios das contas do Governo da Presidência da República do período 2009 a 2013, porque não estavam disponíveis na página da internet do TCU. As demais estavam disponibilizadas em: http://portal.tcu.gov.br/contas/contas-do-governo-da-republica/. Acesso em: 24 Abr. 2017.
} 


\section{O controle público sob suspeita: uma reflexão sobre a estrutura dos tribunais de contas e a eficiência do controle externo sobre a probidade da administração pública}

recomendavam a sua rejeição.

Portanto, fica demonstrada que a forma de investidura dos membros dos Tribunais de Contas prevista na CRFB prejudica a imparcialidade e independência necessárias ao julgamento justo da gestão pública.

Um segundo aspecto da fragilidade institucional refere-se aos critérios da escolha de seus membros, elencados nos incisos II e III do $\S 1^{\circ}$ do artigo 73 da CRFB (transcrito anteriormente), os quais não estabelecem a forma de aferir a idoneidade moral e reputação ilibada dos candidatos às vagas, resultando em alguns Tribunais integrados por juízes com moral e reputações bastante questionáveis.

Não obstante a existência de conselheiros e ministros com condutas irrepreensíveis e com conhecimento especializado, integrando alguns Tribunais, o levantamento feito pela ONG Transparência Brasil sobre a vida pregressa dos membros dos 34 Tribunais de Contas do País aponta para um resultado preocupante (SAKAI; PAIVA, 2014).

De acordo com aquela pesquisa, dos 238 integrantes dos Tribunais de Contas, 53 possuem 104 citações ou condenações na Justiça - algumas originadas de períodos anteriores à investidura nos cargos dos Tribunais e outras durante e também nos Tribunais de Contas, sendo que a maioria dos processos se concentra em conselheiros/ministros com históricos de cargos políticos e apenas $6 \%$ se referem a aqueles que não tem tradição política.

A pesquisa aponta, ainda, que o tipo de ação mais comum é o de improbidade administrativa. São 44 ações que envolvem violações aos princípios administrativos, dano ao erário e enriquecimento ilícito, atingindo 26 conselheiros, seguida do peculato - 12 ações, ações de nulidade da nomeação ao cargo de conselheiro - 8 ações cada, corrupção passiva -7 ações, formação de quadrilha e lavagem de dinheiro - 6 ações cada.

Dos 34 Tribunais de Contas, apenas 6 não têm nenhum conselheiro com citação. Os Tribunais de Goiás e Amapá são os que têm mais conselheiros com pendências na Justiça (4 de 7), seguidos por Sergipe, Roraima, Goiás, Mato Grosso e Rio de Janeiro, com 3 dos 7 conselheiros com pendências.

A constatação de que a maioria dos crimes diz respeito a má utilização de recursos públicos reveste-se da maior gravidade pois coloca em dúvida a legitimidade dos Tribunais de Contas para controlar e fiscalizar atos de improbidade praticados por outros gestores. Esperase que a conduta de quem fiscaliza fique sempre acima de suspeitas que afetem sua credibilidade e, na prática, não é o que está ocorrendo. 
Dessa maneira, em que pese o elevado nível do quadro técnico de auditores/analistas, grande parte deles com especializações, mestrado e doutorado, a fragilidade da norma que trata da composição do órgão deliberativo das entidades fiscalizadoras, aqui demonstrada, resulta no comprometimento da independência e legitimidade das atuações de seus membros e, consequentemente, na ineficácia do controle externo.

\section{O Controle sobre o Controlador}

De acordo com o artigo 70 da CRFB (BRASIL, 1988), a fiscalização da administração pública, incluindo os órgãos da administração direta e indireta, é competência do Congresso Nacional, com o auxílio dos Tribunais de Contas, a quem cabe o controle externo e julgamento da gestão de todos os órgãos.

Por outro lado, naquela mesma seção constitucional não há especificação sobre qual órgão tem competência para fiscalizar os Tribunais de Contas.

Para corrigir essa omissão, as Constituições de cada Estado estabeleceram que o Tribunal de Contas prestará suas contas anualmente à Assembleia Legislativa, no prazo de sessenta dias da abertura da sessão legislativa. Isso significa que, teoricamente, a Assembleia Legislativa fiscaliza o Tribunal de Contas.

Ocorre que a Assembleia legislativa também se insere na jurisdição do Tribunal de Contas e, nessa condição, presta contas à essa Entidade Fiscalizadora, sujeitando-se ao julgamento e à todas as medidas sancionatórias originadas daquele Tribunal e garantidas pela Constituição Federal.

Essa dinâmica criada institucionalmente, na qual o fiscal fiscaliza o fiscalizado que, por sua vez, fiscaliza o fiscal, culmina em prejudicar a isenção e independência necessárias num controle externo e, consequentemente, no julgamento da gestão, ferindo o princípio de segregação de funções, tão exigido pelo TCU durante o exame da legalidade de gestão dos entes sob a sua jurisdição.

O prejuízo na efetividade do controle externo, nesse caso, fica bastante evidente quando se examina as decisões daqueles Tribunais a respeito das contas anuais prestadas pelas Assembleias legislativas de seus respectivos Estados.

É o caso do Tribunal de Contas do Estado de Mato Grosso, que aprovou as contas das gestões 2005 a 2009 da Assembleia Legislativa (Acórdãos n. 3126/2006, 1578/2007, 


\section{O controle público sob suspeita: uma reflexão sobre a estrutura dos tribunais de contas e a eficiência do controle externo sobre a probidade da administração pública}

1103/2008, 3136/2009, 3822/2010) e, logo em seguida, notícias recentes veiculadas na mídia informaram que tramita na $7^{a}$ Vara Criminal de Cuiabá investigação do desvio de $\mathrm{R} \$ 62$ milhões no âmbito daquela Assembleia Legislativa ocorrido no mesmo período (2005 a 2009) envolvendo 34 parlamentares, dentre eles o ex-governador Silval Barbosa e 02 que assumiram o cargo de Conselheiros no Tribunal de Contas (EX-PRESIDENTE, 2017).

De acordo com o depoimento de um dos réus, o ex-deputado José Geraldo Riva, o dinheiro do duodécimo repassado pelo Estado do Mato Grosso para os deputados, era desviado mediante a simulação de compra de utensílios para a Assembleia Legislativa, cujos materiais não eram entregues, ilegalidade essa possível de ser identificada pelo Tribunal de Contas durante a fiscalização das gestões daquele órgão, no período. Todavia, tal não ocorreu.

Em contrapartida, os pareceres prévios favoráveis à aprovação das contas daquele Tribunal referentes às gestões dos mesmos exercícios acima (2005 a 2009) emitidos pelo seu Pleno, foram mantidos na Assembleia Legislativa daquele Estado, aprovando as contas.

Corrobora a ineficiência do controle externo nesse modelo "Controlador $\mathrm{x}$ Controlado x Controlador", a situação do Tribunal de Contas do Estado do Rio de Janeiro, onde 5 conselheiros foram alvos da Operação Quinto do Ouro que investiga esquemas de corrupção, dos quais o presidente da Assembleia Legislativa do Rio, Jorge Picciani (PMDB), é apontado como organizador dos pagamentos de propina.

De acordo com matéria veiculada na mídia (AFFONSO et. al., 2017), aquela Operação investiga o recebimento, por cinco conselheiros do Tribunal de Contas daquele Estado de, no mínimo, R \$1,2 milhão em propina e três esquemas de corrupção nos quais o presidente da Assembleia Legislativa do Rio é apontado como organizador dos pagamentos de propina.

$\mathrm{Na}$ delação do ex-Presidente daquela Corte foi declarado que, mediante acordo da maioria dos seus membros, recursos do Fundo de Reaparelhamento e Modernização dos Tribunais de Contas foram transferidos ao SEAP - Secretaria de Estado de Administração Penitenciária do Rio de Janeiro e, em troca, paga propina a esses Conselheiros.

O tal Fundo mencionado na delação representa um ponto frágil na gestão de recursos públicos no âmbito da administração dos Tribunais de Contas. Os Fundos de 
Reaparelhamento e Modernização foram criados com a finalidade de apoiar os programas e projetos de desenvolvimento e especialização dos recursos humanos do Tribunal de Contas, e ampliar sua capacidade instalada, cujos recursos ali previstos são, dentre outros, a arrecadação de multas aplicadas pelo Tribunal de Contas do Estado ao gestor publico. Assim ocorre nos Tribunais de Contas do Estado de Mato Grosso - Lei n. 8411/2005, do Rio de Janeiro - Lei n. 6113/2011 e de São Paulo - Lei n. 11.077/2002 e outros.

Contudo, não há nenhuma previsão legal da forma e da periodicidade da prestação de contas da aplicação dos recursos daqueles Fundos, tornando vulnerável os seus gerenciamentos.

Alguns Tribunais de Contas, como o do Estado de Mato Grosso, São Paulo e Rio de Janeiro, incluem nos seus demonstrativos contábeis anuais, de forma genérica, o montante das despesas realizadas com os recursos desse Fundo. No entanto, os documentos comprobatórios da arrecadação, das despesas realizadas e os extratos bancários, não são efetivamente analisados e contestados em nenhuma instância.

Todas essas abordagens indicam que não há controle externo sobre os atos do controlador, ou seja, as gestões dos Tribunais de Contas não são efetivamente auditadas por nenhum órgão competente e, mais uma vez, essa omissão ocorre por uma falha institucional.

\section{5. $O$ custo da ineficiência das Instituições}

As instituições, juntamente com as organizações, são responsaveis por definir os custos de transação (transaction costs) e, nessa condição, influenciam o desempenho econômico das sociedades ao longo do tempo (NORTH, 1990).

Conforme demonstrado, as instituições atuais que tratam sobre o controle externo nas administrações públicas brasileiras apresentam falhas graves nos seus textos, o que tem como consequência imediata um custo enorme para o País.

O primeiro custo da ineficiência das leis que dispõe sobre a estrutura dos Tribunais de Contas pode ser identificado nos bilhões de reais desviados dos cofres públicos pelos mesmos gestores que estão sob a jurisdição dos Tribunais de Contas, cuja fiscalização ineficiente não impediu a prática da corrupção.

Não obstante o elevado grau de capacitação do corpo técnico e as modernas ferramentas disponíveis à fiscalização dos auditores públicos, os achados por eles detalhados nos relatórios são, em diversas situações, ignorados pelo corpo deliberativo dos Tribunais de 


\section{O controle público sob suspeita: uma reflexão sobre a estrutura dos tribunais de contas e a eficiência do controle externo sobre a probidade da administração pública}

Contas, que preferem emitir um juízo político sobre a gestão auditada.

Ainda não há dimensão exata dos custos dessa omissão, o que poderá ser apurada ao final das operações de investigações em curso nas justiças das esferas respectivas.

Um outro aspecto do custo da ineficiência das instituições que permeiam os Tribunais de Contas, refere-se ao elevado gasto que a sua manutenção representa à sociedade.

Além do custeio com material de consumo e serviços necessários ao funcionamento daquelas entidades, as despesas realizadas com o pagamento de subsídios e verbas de gratificação aos seus membros também oneram significativamente erário.

Tomando como exemplo o TCE-MT, entidade integrante da amostra selecionada nesta pesquisa, os dados 2017 informam que a remuneração mensal dos Conselheiros é composta do subsídio de $\mathrm{R} \$ 30.471,22$, acrescido de gratificação de direção, auxílio moradia e auxílio alimentação, todos amparados por leis e resolução que, somados, representam $R$ \$ $38.643,87$ por mês a cada um e $\mathrm{R} \$ 69.115,09$ a cada semestre, pois a verba para aquisição de obras técnicas no valor de um subsídio é paga semestralmente, ultrapassando, e muito, o teto constitucional que é de R\$33.736,00 (TRIBUNAL DE CONTAS DO ESTADO DE MATO GROSSO, 2017b).

Além desses subsídios e gratificações, são também pagas aos conselheiros daquele TCE-MT e aos seus servidores efetivos, verbas indenizatórias que, por sua natureza, deveriam indenizar os seus beneficiários dos gastos por eles realizadas no desempenho de suas funções.

Contudo, o exame das legislações que regem a criação da tal verba, denota que elas possuem natureza remuneratória, como ficará demonstrado, a seguir.

Visando sintetizar a pesquisa, a análise neste trabalho recairá apenas sobre a verba indenizatória paga à estrutura deliberativa do TCE-MT que, desde 2015 está composta por 06 conselheiros titulares (porque 01 renunciou depois de se tornar réu em ação de improbidade administrativa), 07 conselheiros substitutos e 04 procuradores de contas.

A verba indenizatória paga aos conselheiros titulares daquele TCE foi instituída através da Lei n. 8402/2005 e, posteriormente, pelas Leis 9493/2010, 9626/2011 e 9866/2012. Conforme esses textos legais, a tal verba é paga mensalmente aos membros dos órgãos do poder legislativo, significando que abrange, além dos Conselheiros, também os deputados Estaduais, como uma forma compensatória às despesas inerentes as suas atividades.

Atualmente, os valores mensais das verbas indenizatórias a que eles tem direito estão previstos em, até, $\mathrm{R} \$$ 65.000,00 (Decreto legislativo n. 42/2015). No TCE-MT a 
Decisão Administrativa n. 09/2015 do TCE-MT definiu o valor dessa verba em 67,32\% do subsídio dos conselheiros titulares, correspondendo a $\mathrm{R} \$ 20.511,83$ e, ainda, $66,47 \%$ aos conselheiros substitutos e $67,52 \%$ aos procuradores de contas.

Ocorre que não há nas legislações que criaram e aumentaram a tal verba, nenhuma previsão da obrigatoriedade de prestação de contas e, muito menos, da forma como isso deve ocorrer. Por isso, não há nenhuma comprovação de que os valores recebidos por esses membros do corpo deliberativo do TCE-MT tiveram como finalidade indenizar gastos realizados no exercício das suas funções.

Importante lembrar que a ausência da prestação de contas fere frontalmente o disposto no Parágrafo único do artigo 70 da CRFB (BRASIL,1988) que diz:

\footnotetext{
Art. $70[\ldots]$

Parágrafo único. Prestará contas qualquer pessoa física ou jurídica, pública ou privada, que utilize, arrecade, guarde, gerencie ou administre dinheiros, bens e valores públicos ou pelos quais a União responda, ou que, em nome desta, assuma obrigações de natureza pecuniária. (Redação dada pela Emenda Constitucional no 19, de 1998)-Destacou-se.
}

Nesse caso, não havendo prestação de contas, aquela verba representa remuneração recebida pelos membros do TCE-MT disfarçada de verba indenizatória e, nessa condição, não incide imposto de renda prejudicando a arrecadação do Estado, não sofre retenção de parcela previdenciária e, ainda burla a verificação do limite de gasto com pessoal (L.C. n. 101/2000).

Para se ter uma idéia do que representa o montante gasto com o pagamento das verbas indenizatórias aos integrantes do corpo deliberativo do TCE-MT, fez-se um levantamento dos valores, tomando como base o exercício 2015 e obteve-se o montante anual de $\mathrm{R} \$ 5.558 .228,09$.

O mais grave é que essa despesa ocorre sem nenhuma prestação de contas que viesse justificar a natureza indenizatória daquela verba, levando a concluir que, embora legal (criada por lei), é imoral. Contudo, não havendo controle na gestão dos Tribunais de Contas, como demonstrado na seção anterior, a avaliação da moralidade desse gasto segue inexistente.

Todos os aspectos aqui abordados denotam que a estrutura dos Tribunais de Contas, apoiada nas instituições vigentes, representa um elevado custo para a sociedade brasileira.

\section{Conclusão}

A análise nos principais marcos regulatórios que tratam da estrutura e atuação dos Tribunais de Contas no Brasil, como proposta nesta pesquisa, demonstrou diversas 


\section{O controle público sob suspeita: uma reflexão sobre a estrutura dos tribunais de contas e a eficiência do controle externo sobre a probidade da administração pública}

imperfeições daquelas instituições que refletem diretamente na ineficiência do controle externo dos recursos públicos e contribuem, em grande parte, na ocorrência dos desvios e corrupções rotineiras que vem sendo divulgados na mídia atual.

Não há dúvida de que as regras atuais que estruturam os Tribunais de Contas representam um modelo obsoleto para os padrões de um Estado moderno e eficiente exigido pela sociedade, confirmando assim a hipótese levantada no início desta pesquisa.

O exame dos dispositivos constitucionais que regulam o tema, descrito na seção 3 deste trabalho, evidenciou diversos pontos críticos demonstrados neste trabalho. Atribuir a investidura dos cargos vitalícios de conselheiros/ministros, à livre escolha de representantes do poder legislativo e do chefe do poder executivo, além de ir na contramão da regra geral de concurso para preenchimento de cargos públicos, anula a independência dos membros dos Tribunais de Contas tão necessária na fiscalização da coisa pública.

Da mesma forma, os frágeis critérios de escolha dos candidatos ao cargo, elencados nos incisos do $\S 1^{\circ}$ do artigo 37 da CRFB, eliminam qualquer tentativa de assegurar retidão de caráter de seus ocupantes. Sem parametrização, não há como garantir moral idônea e reputação imaculada daqueles que irão julgar gestões públicas e o resultado é o envolvimento de alguns membros do Tribunal de Contas em operações investigatórias na justiça, como abordado naquela seção 3, abalando a credibilidade do órgão.

O outro ponto crítico institucional relacionado à estrutura dos Tribunais de Contas diz respeito a ausência de controle sobre a gestão daquelas entidades. Como abordada na seção 4 desta pesquisa, a gestão administrativa dos Tribunais de Contas não se submete a uma efetiva fiscalização por um órgão isento e independente e corresponde a mais uma anomalia institucional.

Essa imperfeição estrutural revela-se da maior gravidade diante de despesas com pagamentos de verbas indenizatórias aos membros do TCE-MT, descritas na seção 5 e que mereciam uma avaliação criteriosa à luz do princípio constitucional de moralidade.

Confirmando a teoria de Douglass North, as imperfeições institucionais no segmento do controle da administração pública demonstrada neste trabalho tem como consequência um elevado custo à Nação, quer pelos desvios de recursos facilitados pela ineficiência de atuação dos Tribunais de Contas, como também pelo elevado valor destinado a manutenção da estrutura daquela entidade fiscalizadora, demonstrado na seção 5.

Essa percepção leva a refletir também sobre a relação custo/benefício dos Tribunais 
de Contas e indagar se o retorno dos valores aos cofres públicos originados das suas atuações punitivas (restituição de valores, multas aplicadas) e preventivas, compensa o elevado custo da sua estrutura, onerado especialmente por verbas extras de remuneração, instituídas e tratadas equivocadamente como indenizações.

A banalização da prática de corrupção em diversos órgãos de todas as esferas do país corrobora essa tese e demonstra que, definitivamente, a gestão dos recursos públicos saiu do controle dos Tribunais de Contas. Vale afirmar que o elevado nível de capacitação do corpo técnico daquela entidade fiscalizadora garante a excelência das auditorias por eles realizadas; mas não assegura a mesma qualidade na ponta, onde o julgamento da gestão se dá. Pode-se dizer que há eficiência na fiscalização, mas não há no controle da administração pública.

Se as escolhas no passado influenciam o presente e mudanças institucionais afetam a trajetória de um país (NORTH, 1990), então é imperiosa uma agenda de inovação institucional sobre o controle da administração pública, de maneira a coibir definitivamente as relações personalistas e dar lugar à impessoalidade no trato da coisa pública.

E mais, é preciso ousar, à luz da experiência brasileira atual. As inovações institucionais que se esperam exigem mudanças profundas no sistema de controle externo e não devem se restringir ao estabelecimento de rito para a escolha dos ministros e conselheiros dos Tribunais de Contas no âmbito do poder legislativo, como defendida na campanha "Conselheiro Cidadão" apoiada pelo TCE-MT. A impessoalidade da escolha daqueles integrantes somente pode ser garantida se a investidura for através de concurso público.

As mudanças nesse tema devem ir muito além e considerar, inclusive, a extinção dos Tribunais de Contas como órgão deliberativo administrativo. Nesse caso, a fiscalização da administração pública permaneceria à cargo do corpo técnico hoje ali existente, que detém o conhecimento necessário para auditar as gestões dos órgãos; e o julgamento da gestão auditada caberia à instância superior competente, já existente na estrutura federal e estadual.

Algumas mudanças institucionais sobre o tema constam em Propostas de Emendas Constitucional - PEC tramitando na Câmara dos Deputados, como a PEC 329/2013 que sugere algumas alterações no artigo 73 da CRFB e a PEC 40/2016, que padroniza a auditoria de controle externo; contudo, as alterações ali propostas não nos parecem suficientes para elidir os erros na trajetória dos Tribunais de Contas até aqui.

Por fim, os pontos críticos do controle externo da administração pública identificados neste trabalho exigem mudanças institucionais efetivas, a fim de que os Tribunais de Contas 


\section{O controle público sob suspeita: uma reflexão sobre a estrutura dos tribunais de contas e a eficiência do controle externo sobre a probidade da administração pública}

não se convertam numa "instituição de ornato aparatoso e inútil", como temia o patrono daquelas Entidades, Rui Barbosa.

\section{Referências*}

AFFONSO, Júlia et al. Operação O Quinto do Ouro, da PF, prende conselheiros do TCE e leva Picciani para depor. Jornal Estadão, mar. 2017 Disponível em: $<$ http://politica.estadao.com.br/blogs/fausto-macedo/pf-vai-as-ruas-e-mira-no-tribunal-decontas-do-rio/> Acesso em: 20 abr. 2017.

BARBOSA, Rui. Exposição de Motivos de Rui Barbosa sobre a criação do TCU. In: Revista do Tribunal de Contas da União. Ed. Instituto Serzedello Corrêa. Brasília, v. 30, n. 82, out/dez. 1999. Pág. 253-262. Brasília, 1999.

BRASIL. Constituição da República Federativa. Brasília, 1988. Disponível em: <http://www.planalto.gov.br/ccivil_03/constituicao/constituicao.htm >. Acesso: 15 mar. 2017.

BRITTO, Carlos Ayres. O Regime Constitucional dos Tribunais de Contas. In: O Novo Tribunal de Contas: Órgão Protetor dos Direitos Fundamentais. 3a. Edição. Editora Fórum. Belo Horizonte, 2005.

CPI Entrega relatório e aponta desvio de $\mathrm{R} \$ 541$ milhões em obras da copa. G1 Mato Grosso. Cuiabá, out. 2016. Disponível em: <http://g1.globo.com/matogrosso/noticia/2016/10/cpi-entrega-relatorio-e-aponta-desvio-de-r-541-milhoes-em-obras-dacopa.html>. Acesso em: 24 abr. 2017.

EX-PRESIDENTE da ALMT diz que ele e 33 deputados recebiam 'mensalinho'. G1 Mato Grosso. Cuiabá, abr. 2017. Disponível em: <http://g1.globo.com/matogrosso/noticia/2017/04/ex-presidente-da-almt-diz-que-ele-e-33-deputados-recebiammensalinho.html >. Acesso: 15 maio 2017.

HOLANDA, Sérgio Buarque. Raízes do Brasil. São Paulo: Companhia das Letras, 1995.

NORTH, Douglass \& DAVIS, L. Institutional Change and American Economic Growth. Cambridge University Press, Cambridge, 1971.

; THOMAS, Robert P. The rise of the western world: A new economic history. Cambridge University Press. 1973.

\footnotetext{
* Baseadas nas normas NBR 6023, de 2002 e NBR 10520, de 2002 da Associação Brasileira de Normas Técnicas (ABNT).
}

Institutions, Institutional Change and Economic Performance. New York: Cambridge University Press, Cambridge. 1990.

Intitutions. In: Journal of Economic Perspectives - Volume 5 , Number 1 -Winter 1991-Pages 97-112. Published by: American Economic Association.

SAKAI, Juliana; PAIVA, Natália. Quem são os conselheiros dos Tribunais de Contas? Transparência Brasil. São Paulo, abr. 2014. Disponível em: 
<http://www.transparencia.org.br/downloads/publicacoes/TBrasil\%20-

$\% 20$ Tribunais\%20de\%20Contas\%202016.pdf > . Acesso em: 14 maio 2017.

SECRETARIA DE SEGURANÇA PÚBLICA DO ESTADO DE MATO GROSSO. Polícia Civil deflagra $4^{\text {a }}$ fase da Operação Sodoma. Cuiabá, set. 2016. Disponível em: <http://www.mt.gov.br/-/5018745-policia-civil-deflagra-4-fase-da-operacao-sodoma>.

Acesso em: 20 abr. 2017.

SOARES, Denise. Juiz afasta conselheiro acusado de pagar R $\$ 4$ milhões por vaga no TCE. G1 Mato Grosso. Cuiabá, jan. 2017. Disponível em: <http://g1.globo.com/matogrosso/noticia/2017/01/juiz-afasta-conselheiro-acusado-de-pagar-r-4-milhoes-por-vaga-notce.html >. Acesso em: 5 maio 2017.

TRIBUnAl DE CONTAS DO ESTADO. Pesquisa de Processo. Cuiabá, 2017a. Disponível em: <http://www.tce.mt.gov.br/consulta_es>. Acesso em: 24 abr. 2017.

.Portal Transparência. Cuiabá, 2017b. Disponível em: <https://sic.tce.mt.gov.br/1/assunto/listaSubItem/id_assunto/3 >. Acesso em: 24 abr. 2017.

TRIBUNAL DE CONTAS DA UNIÃO. Ouvidoria. Dúvidas Frequentes. Autonomia e Vinculação. Brasília, [2013?]. Disponível em: <http://portal.tcu.gov.br/ouvidoria/duvidasfrequentes/autonomia-e-vinculacao.htm> . Acesso em: 20 abr. 2017.

WEBER, Max. Economia e Sociedade. Volume 1. Brasília, Editora da Unb, 1991.

Economia e sociedade: fundamentos da sociologia compreensiva. Volume 2.

Brasília, Ed Unb. 1999, 2009 (reimpressão). 